12 Singh A, Jolly SS, Bansal BC. Skeletal fluorosis and its neurological complications. Lancet 1961;i:197-200.

13 Riggs BL, Hodgson DL, Kelly PJ, Johnson KA, Taves D. Treatment of primary osteoporosis with fluoride and calcium, clinical tolerance and fracture occurrence. JAMA 1980;243:446-9.

14 Shung-Guan Cu-min. The nonskelectal lesion of endemic fluorosis (in Chinese). Chinese J Inter Med
1982;21:217-9.

15 Ding Lou-Ian. The nervous systemic complication of chronic fluorosis (in Chinese). Chinese Journal of Endemiology 1983;2:97-8.

$16 \mathrm{Hu}$ Yu-huan. Direct damage on nervous system by fluorosis, (in Chinese). The Compilation of The First Conference on Neuropsychiatric Diseases in Xinjian 1982:86-8.

\title{
Little's disease
}

Every student is taught about Little's spastic diplegia, but how many know that William John Little (1810-94) was himself afflicted with a congenital equinus deformity of his left foot? He was founder of the Royal Orthopaedic Hospital and Senior Physician to the London Hospital. His several disquisitions ${ }^{1-3}$ are quite brilliant and repay study in full.

"I have witnessed so many cases of deformity, mental and physical, traceable to causes operative at birth, that I consider the subject worthy of notice ${ }^{3}$ of the Obstetrical Society." He mentions 200 cases encountered in 20 years of orthopaedic practice. He stressed the "larger proportion of dead, stillborn, apoplectic, or asphyxiated at birth have been rendered so by interruption of the proper placental relation of the foetus to the mother, and non-substitution of pulmonary respiration, than from direct mechanical injury to the brain and spinal cord." The consequences were "internal congestions, capillary extravasations, serous effusions which correspond with. . . asphyxia, suspended animation, apoplexy, torpidity, tetanic spasms, convulsions of newborn children, and the spastic rigidity, paralysis, and idiocy subsequently witnessed."

"The flexors and abductors of the thighs, flexors of the knees, and the gastrocnemii preponderate. . thighs cannot be completely abducted or extended, the knees cannot be straightened, nor the heels applied to the ground. The elbows are semiflexed, wrists partially flexed and pronated and fingers incapable of perfect voluntary direction. . . upper extremities sometimes appear unaffected. . . Muscles of speech are commonly involved,. . . articulation is slow and difficult. . . in the majority of cases the intellect suffers - from the slightest impairment up to entire imbecility."

Little relates presentations with convulsions, opisthotonus or laryngismus in the early days and the delay in recognising paralysis until the child starts to walk in milder cases; he describes the deformities of posture, trunk and the impediment in walking. He had sparse necropsy evidence "Case LX showing cicatrised apoplexies on surface and interior surfaces of the brain. . . effusion of blood in both ventricles of brain-a true apoplexy (case XLI-a precipitate labour). But, curiously, he concluded "that the spinal meningitic and myelitic affections may play a considerable part in the phenomena of spastic rigidity." His finale is a brief but optimistic reference to "therapeutic effects producing amelioration surprising to those who have not watched such cases."

JMS PEARCE

\section{References}

1 Little WJ. Course of Lectures on the deformities of the human frame. Lancet 1943;i:5-8; ibid 38-44; ibid 78-82 et seq.

2 Little WJ. On the nature and treatment of deformities of the human frame: being a course of lectures delivered at the Royal Orthopaedic Hospital in 1843: with numerous notes and additions to the present time. London: Longman, 1853.

3 Little WJ. On the influence of abnormal parturition, difficult labours, premature birth, and asphyxia neonatorum, on the mental and physical condition of the child especially in relation to deformities. Transactions of the Obstetrical Society of London, 1861;3:293-344. 